\title{
REVIEW
}

\section{Neurosteroid metabolism in the human brain}

\author{
Birgit Stoffel-Wagner \\ Department of Clinical Biochemistry, University of Bonn, 53127 Bonn, Germany
}

(Correspondence should be addressed to Birgit Stoffel-Wagner, Institut für Klinische Biochemie, Universitaet Bonn, Sigmund-Freud-Strasse 25, D-53127 Bonn, Germany; Email: birgit.stoffel-wagner@ukb.uni-bonn.de)

\begin{abstract}
This review summarizes the current knowledge of the biosynthesis of neurosteroids in the human brain, the enzymes mediating these reactions, their localization and the putative effects of neurosteroids. Molecular biological and biochemical studies have now firmly established the presence of the steroidogenic enzymes cytochrome $\mathrm{P} 450$ cholesterol side-chain cleavage $\left(\mathrm{P}_{4} 50_{\mathrm{SCC}}\right)$, aromatase, $5 \alpha$-reductase, $3 \alpha$-hydroxysteroid dehydrogenase and $17 \beta$-hydroxysteroid dehydrogenase in human brain. The functions attributed to specific neurosteroids include modulation of $\gamma$-aminobutyric acid A $\left(\mathrm{GABA}_{\mathrm{A}}\right)$, N-methyl-D-aspartate (NMDA), nicotinic, muscarinic, serotonin (5-HT $)$, kainate, glycine and sigma receptors, neuroprotection and induction of neurite outgrowth, dendritic spines and synaptogenesis. The first clinical investigations in humans produced evidence for an involvement of neuroactive steroids in conditions such as fatigue during pregnancy, premenstrual syndrome, post partum depression, catamenial epilepsy, depressive disorders and dementia disorders. Better knowledge of the biochemical pathways of neurosteroidogenesis and their actions on the brain seems to open new perspectives in the understanding of the physiology of the human brain as well as in the pharmacological treatment of its disturbances.
\end{abstract}

European Journal of Endocrinology 145 669-679

\section{Introduction}

Steroid hormones are mainly synthesized in the adrenal glands, the gonads and the feto-placental unit. They can easily cross the blood-brain barrier due to their high lipid solubility. The brain is an important target organ of steroid hormones. Moreover, an extensive steroid metabolism occurs in the brain and several brain regions are well equipped with enzymes necessary for steroid hormone biosynthesis (1-4). Steroid hormones play an important role in the development, growth, maturation and differentiation of the brain.

Although, as in the case of aromatase, the activity of steroidogenic enzymes had already been identified in human fetal brain tissue 25 years ago (5), the majority of biochemical, physiological and behavioral studies on aromatase in brain tissue had been carried out in rodents or other vertebrate species. The difficulty in obtaining fresh human brain tissue, coupled with presumably low expression or activity of the respective enzymes, has so far precluded studies in humans. This is also the case with other steroidogenic enzymes. Steroidogenesis requires numerous sequential enzymatic reactions to convert cholesterol to glucocorticoids, mineralocorticoids or sex hormones. Since the steroids produced within a tissue depend upon the enzymes present in this tissue, only systematic studies on the expression of all relevant steroidogenic enzymes would allow insight into the steroidogenic pathways and the capacity within the respective tissue, i.e. the human brain. Although reports on the expression and activity of the most important steroidogenic enzymes in the human brain have been published in recent years, a comprehensive review is still missing. This article reviews the current knowledge of steroid hormone metabolism within the human brain and the evidence we have for its importance.

Animal studies have shown that steroids synthesized de novo in the central nervous system can affect multiple brain functions (i.e. neuroendocrine and behavioral functions) via intracellular receptors that regulate transcriptionally directed changes in protein synthesis. These physiological actions generally occur within hours or days. In addition to the classic sites of steroid synthesis, neurosteroids can rapidly alter excitability of the central nervous system through binding to neurotransmitter-gated ion channels, thus modulating $\gamma$-aminobutyric acid A $\left(\mathrm{GABA}_{\mathrm{A}}\right)$ and N-methyl-D-aspartate (NMDA) receptors (6-8). These actions occur within seconds or milliseconds via ligand or voltage-gated ion channels. Compounds that have direct nongenomic effects on neuron excitability are referred to as neuroactive steroids (9). Neurosteroids, 
by definition, are steroids that still accumulate in the brain in the absence of steroidogenic glands and are synthesized in the brain from endogenous precursors by enzymes that are present in situ (6). Neurosteroids can be further classified into two groups: neuroactive and neuroinactive steroids. The term 'neuroactive' steroids refers to steroids that are active on neural tissue. They may be synthesized in the brain or in endocrine glands. The term 'neuroinactive' steroids refers to steroids synthesized in the brain that are inactive on neural tissues. In 1941, Selye first described the anesthetic and sedative properties of progesterone and some of its metabolites (10). The potencies of neuroactive steroids in biochemical and electrophysiological investigations correlate with their sedative, anticonvulsant, and anxiolytic effects in vivo. There are a number of reviews concerning the biosynthesis and metabolism of neurosteroids and neuroactive steroids in animals (7-9, 11-13).

\section{Steroid conversions in the human brain}

\section{Cytochrome $P 450$ cholesterol side-chain cleavage (P450 $\left.{ }_{\text {scc }}\right)$}

The first and rate-limiting step in the synthesis of steroid hormones is the conversion of cholesterol to pregnenolone, catalysed by the enzyme cytochrome $\mathrm{P} 450_{\text {SCC }}$. Human $\mathrm{P}^{4} 50_{\text {SCC }}$ is encoded by a single gene on chromosome 15, the CYP11A1 gene (14). In addition to the major sources of steroid production, the adrenal glands and gonads, $\mathrm{P} 450_{\mathrm{SCC}}$ mRNA and enzyme are also present in the placenta, the primitive gut and in the brain (15-17). However, the major role of $\mathrm{P} 450_{\mathrm{SCC}}$ in the brain is probably the regulation of brain neurosteroid levels (18). Recently, we investigated the expression of CYP11A1 mRNA in tissue specimens from temporal and frontal neocortex, subcortical white matter from the temporal lobe and in the hippocampus from children and adults $(19,20)$. In these brain areas, CYP11A1 mRNA was expressed in significant amounts in all tissue samples investigated, at a rate, however, $\approx 200$ times lower than in adrenal tissue, which is known for the highest CYP11A1 expression. Thus, CYP11A1 mRNA expression in the human brain is within the range previously estimated for rat brain in qualitative RT-PCR experiments $(17,18,21)$. In humans, CYP11A1 mRNA concentrations in the temporal lobe increase markedly during childhood and reach adult levels at puberty (19). CYP11A1 mRNA concentrations were significantly higher in the temporal and frontal neocortex as well as in the hippocampus of women compared with those of men $(19,20)$. These data demonstrated for the first time an age- and sex-dependent expression of CYP11A1 mRNA in the human brain. Few data are available on the relative amount of CYP11A1 mRNA in the brain of male and female animals, but qualitative studies report no obvious sex differences in rats $(17,22)$. Due to the insensitivity of qualitative RT-PCR in detecting differences in mRNA expression at high cycle numbers, a careful quantitative re-examination of results obtained in rat brain with respect to sex differences of CYP11A1 mRNA expression seems to be necessary. Whereas in situ hybridization and cell culture experiments in rat brain demonstrated predominant CYP11A1 expression in the subcortical white matter $(21,23)$, no such differences could be detected between neocortex and subcortical white matter tissue in the human brain (19). The presence of CYP11A1 mRNA in human brain tissue provides evidence that pregnenolone can be produced in the central nervous system.

\section{Aromatase}

Cytochrome P450 aromatase, which catalyses the conversion of androgens to estrogens in specific brain areas (3), is the product of the CYP19 gene, which has been cloned and sequenced $(24,25)$.

In the brain, androgens may be metabolized following two different major pathways. First, the aromatase pathway (transformation of testosterone into estradiol and of androstenedione into estrone), and secondly, similar to the one present in the majority of the peripheral androgen dependent structures, e.g. prostate, the $5 \alpha$-reductase pathway (transfomation of testosterone into dihydrotestosterone).

Aromatase activity itself has been detected only in a few fetal brain specimens (26-28). Previously published data demonstrated aromatase activity in human temporal and in frontal brain areas (29). The authors studied biopsy materials removed at autopsy from normal adult control subjects and from patients with Alzheimer's disease. Temporal aromatase activity was always significantly higher than frontal aromatase activity regardless of sex and/or disease state. This difference was also confirmed by our own studies on the expression of temporal and frontal CYP19 mRNA in fresh brain tissue specimens from adult patients with epilepsy undergoing neurosurgery (30). CYP19 mRNA was not only expressed in temporal and frontal neocortex, but also in the human hippocampus and in subcortical white matter of the temporal lobe $(30$, 31). Sex specific differences in CYP19 mRNA expression could be observed in none of these brain areas. In our laboratory, aromatase activity in the temporal lobe was recently characterized in a similar cohort of patients with epilepsy (32). Aromatase activity was present in all tissue specimens under investigation. We demonstrated a specific, dose-responsive and competitive inhibition of its activity by atamestane, which is a known specific and competitive inhibitor of placental aromatase activity (33). Aromatase activity in the human brain was low compared with its high activity in the placenta. However, rates of aromatase activity in the brain were in the same order of magnitude as in 
human adipose and testicular tissue $(34,35)$. Subsequent experiments with cerebral neocortex and subcortical white matter specimens of children and adults revealed significantly higher aromatase activity in the cerebral neocortex than in the subcortical white matter (32). This difference could not be found for CYP19 mRNA expression in the human temporal lobe (31). However, in the human temporal neocortex, CYP19 mRNA concentrations were significantly lower in children than in adults (31), a finding which could not be confirmed by measurement of aromatase activity (31). These contradictory findings indicate that aromatase might be regulated at the post-translational level.

Expression of the CYP19 gene, involving alternative splicing of multiple forms of exon 1, has been demonstrated to contribute to tissue-specific expression of aromatase (36-40). Honda and co-workers found that the aromatase gene in human brain is expressed with a brain-specific exon 1 and promotor, using poly (A) + RNAs in human amygdala and hippocampus (40). However, a recent study (41) demonstrated that the expression of aromatase in human brain is not necessarily under the control of the brain specific exon 1 or exon $1 \mathrm{f}$ as proposed by Honda et al. (40). Instead, Sasano and co-workers found different patterns of utilization of exon 1 in different areas of the human brain tissue derived from autopsies (41). Hypothalamic and/or limbic structures utilized exon $1 \mathrm{f}$ and/or $1 \mathrm{~d}$ (gonadal type) while other areas (pons, frontal lobe) utilized $1 \mathrm{~b}$ (fibroblast type). There were no differences of utilization of exon 1 and mRNA expression of aromatase between female and male brains. Total amounts of aromatase mRNA varied among the brain regions and individuals under investigation. Due to the limited number of patients ( 4 men, 2 women), a statistical comparison could not be carried out. The authors suggest that the variability may possibly be caused by the effects of terminal and/or postmortem changes on the preservation of mRNA in tissue specimens.

\section{$5 \alpha$-Reductase}

Numerous animal studies have shown that in the central nervous system progesterone is rapidly metabolized to $5 \alpha$-dihydroprogesterone ( $5 \alpha$-DHP), which is then further reduced to the potent neurosteroid $3 \alpha, 5 \alpha-$ tetrahydroprogesterone $(3 \alpha, 5 \alpha \mathrm{THP})(8)$. These reductive conversions are catalysed by $5 \alpha$-reductase and

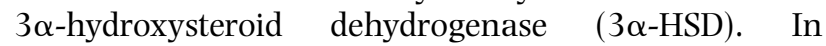
humans, two isozymes of $5 \alpha$-reductase, which differ in tissue distribution and biochemical characteristics as well as in their responsiveness to specific inhibitors of their enzymatic activity, have been identified $(42,43)$.

The majority of physiological and biochemical studies on the expression of $5 \alpha$-reductase in the brain were carried out in rodents and other vertebrate species
(1, 2, 44, 45). However, some investigators documented $5 \alpha$-reductase activity in human fetal brain (4648 ), but $5 \alpha$-reductase activity in the brain of adults was only demonstrated in a few frontal lobe and temporal lobe tissue specimens $(49,50)$.

Recently, we have demonstrated the predominant expression of $5 \alpha$-reductase type 1 mRNA in a large series of human temporal neocortex and subcortical white matter as well as hippocampal tissue specimens obtained from patients with chronic temporal lobe epilepsy $(51,52)$. The expression levels were about 100 times lower than in human liver tissue. $5 \alpha$-Reductase type 2 mRNA was not expressed. Another study reported on $5 \alpha$-reductase type 1 mRNA expression in a few human cerebellum, hypothalamus and pons tissue specimens which were collected postmortem (53). Also, a predominant expression of $5 \alpha$-reductase type 1 mRNA was found in rat brain $(2,54)$.

Previously, it was reported that $5 \alpha$-reductase type 1 mRNA is expressed in rat brain at all stages of brain development and in adulthood, with a small increase around the time of birth, whereas $5 \alpha$-reductase type 2 mRNA is only transiently expressed during the late fetal and early postnatal life (55). The expression patterns of this isoform overlapped the secretory profile of testosterone. The authors hypothesize that increased levels of circulating androgens occurring in male rats around the time of birth could modulate $5 \alpha$-reductase type 2 expression. Hence, transient androgen-regulated expression of $5 \alpha$-reductase type 2 may be important for sexual differentiation of the brain and for the formation of anxiolytic/anesthetic steroids originating from $3 \alpha$-hydroxylation of $5 \alpha$-reduced derivates of progesterone involved in the stress responses associated with parturition. However, we still do not know whether $5 \alpha$-reductase type 2 mRNA might be expressed transiently during fetal or early postnatal life within the human brain.

In our laboratory, we also measured $5 \alpha$-reductase activity in human temporal neocortex and subcortical white matter tissue specimens $(51,56)$. We used androstendione as the substrate; in a former study on human fetal brain tissue almost the same enzyme activity rates were found with either androstenedione or progesterone as the substrate (46). While enzyme activity was present in all tissue specimens under investigation, the apparent $K_{\mathrm{m}}$ values and the $\mathrm{pH}$ profile substantiated the predominant expression of the type 1 isoform. Furthermore, we investigated the inhibitory effects of MK386, a specific inhibitor of the $5 \alpha$-reductase type 1 isoform, and of finasteride, a specific inhibitor of the $5 \alpha$-reductase type 2 isoform on $5 \alpha$-reductase activity (56). MK386 was a strong inhibitor of human brain tissue $5 \alpha$-reductase activity, with an $\mathrm{IC}_{50}$ value of $2.0 \mathrm{nmol} / \mathrm{l}$, whereas finasteride turned out to be a poor inhibitor of the reaction, with an $\mathrm{IC}_{50}$ value of $142.8 \mathrm{nmol} / \mathrm{l}$ (56). Moreover, we observed a potent inhibition of the $\mathrm{pH}$-dependent 
reaction by MK386 but not by finasteride; this further substantiates an, at least predominant, activity of the $5 \alpha$-reductase type 1 isozyme in the human brain (56). There were no sex-specific differences in the expression levels of $5 \alpha$-reductase type 1 mRNA in human temporal lobe and hippocampal tissue or in the activity of $5 \alpha$-reductase $(51,52,56)$. These findings are consistent with previous animal studies, where no significant sex specific differences concerning $5 \alpha-$ reductase activity were found in neural tissue of rhesus macaques during fetal development (57) or in rats during postnatal development $(58,59)$.

\section{$3 \alpha$-Hydroxysteroid dehydrogenase}

Multiple cDNAs encode proteins related to $3 \alpha$-HSD in humans (60). However, three functional $3 \alpha-\mathrm{HSD}$ isozymes (type 1,2 and 3) have been characterized on the basis of their affinity for $5 \alpha$-dihydrotestosterone (61-64).

Recently, we could only demonstrate the expression of the mRNA of the type 2 isozyme of $3 \alpha$-HSD in the hippocampus and the temporal lobe of patients with temporal lobe epilepsy, whereas the mRNA of the type 1 isozyme of $3 \alpha$-HSD was not expressed $(52,56) .3 \alpha-\mathrm{HSD}$ type 2 is thought to be responsible for the production of neurosteroids (61), whereas the type 1 isozyme is expressed exclusively in the liver. In liver metabolism, $3 \alpha$-HSD type 1 plays an essential role leading to physiologically inactive metabolites of steroid hormones. The mRNA expression levels of $3 \alpha$-HSD type 2 in the human hippocampus were approximately one fifth of that in human liver tissue. For the quantification of $3 \alpha$-HSD type $2 \mathrm{mRNA}$ there was no need for a nested competitive RT-PCR assay as required for $5 \alpha-$ reductase type $1 \mathrm{mRNA}$. This emphasizes the fact that the mRNA expression levels of $3 \alpha-\mathrm{HSD}$ are much higher than those of $5 \alpha$-reductase type 1 mRNA. This is also consistent with the suggestion that $5 \alpha$-reduction is the rate-limiting step in the production of $3 \alpha, 5 \alpha-$ reduced metabolites of progesterone (65).

In accordance with data on $3 \alpha$-HSD activity in the rat brain, expression of $3 \alpha$-HSD type $2 \mathrm{mRNA}$ in the human hippocampus did not differ between the sexes $(52,66)$.

Penning and co-workers demonstrated that, apart from $3 \alpha$-HSD type 2 being expressed in human brain, $3 \alpha$-HSD type 3 and $20 \alpha(3 \alpha)$-HSD (EC 1.1.1.149) are also expressed to a larger extent in the human brain (64). Moreover, they showed that all human $3 \alpha-\mathrm{HSD}$ isoforms and the human $20 \alpha$-HSD act as 3-, 17- and 20-ketosteroid reductases as well as 3-, 17- and 20hydroxysteroid oxidases. Based on spectrophotometric and radiometric data, the authors concluded that all isoforms were capable of producing the neuroactive tetrahydrosteroids that modulate the $\mathrm{GABA}_{\mathrm{A}}$ receptor. Thus, the meaning of the differential expression of the single isoforms is less established than ever.

\section{$17 \beta$-Hydroxysteroid dehydrogenase}

The seven human isozymes of $17 \beta$-hydroxysteroid dehydrogenase (17ß-HSD), which have so far been cloned, play a major role in the regulation of the biological activity of sex hormones. They are essential for the biosynthesis of the strong androgens and estrogens, testosterone and estradiol from their weaker precursors androstenedione and estrone $(67,68)$. These conversions are reversible and thus can lead to a deactivation of the respective sex hormones (69). The different isozymes show an individual cell-specific expression and substrate specificity. The importance of the $17 \beta$-HSD activity in the maintenance of physiological levels of estradiol and testosterone is reflected by the ubiquitous distribution of $17 \beta-H S D$ in peripheral tissues (70).

$17 \beta$-HSD activity in the human brain was reported about 30 years ago $(49,71)$. However, studies on the expression of the enzyme in the human brain are still rare. Western immunoblot analysis revealed the presence of $17 \beta$-HSD 1 in human fetal brain (72). Recently, we demonstrated the expression of 17ß-HSD 1, 3, 4 and 5 mRNA in the human temporal lobe and hippocampus, whereas an in tandem pseudogene of $17 \beta$-HSD 1 and 17ß-HSD 2 mRNA was not expressed (73, 74). Moreover, we characterized androgenic and estrogenic 17ß-HSD activity in the human temporal lobe and found the NADPH-dependent reduction of androstenedione and estrone as well as the NAD-dependent oxidation of testosterone and estradiol (75). Substrate specificity, cofactor requirement patterns, $\mathrm{pH}$ optima and kinetic properties suggest the activity of at least two isozymes, namely the activating $17 \beta$-HSD 3 and the deactivating $17 \beta$-HSD 4 , in the human brain. There was no sexual dimorphism in the expression or activity of $17 \beta$-HSDs. However, the expression levels of $17 \beta-H S D$ 3, 4 and 5 mRNAs as well as the conversion of androstenedione, testosterone, estrone and estradiol were signifiantly higher in the subcortical white matter than in the cerebral neocortex (73-75). The predominant expression of $17 \beta$-HSD in the subcortical white matter suggests that glial cells could play a role in the biosynthesis and deactivation of sex steroids in the brain. Among a host of potential functions of glia, glial cells are involved in the formation of myelin, suggesting a possible correlation between sex steroids, these enzymatic activities and the formation or functions of myelin.

In a recent study on the human 17ß-HSD 7 gene (HSD17B7), its promotor revealed binding sites for brain-specific transcription factors corresponding to expression domains in the developing brain as identified by in silico Northern blot (68). 17ß-HSD 8 expression has not yet been investigated in the human brain.

\section{Other steroidogenic enzymes}

Other important steroidogenic enzymes are $3 \beta$-hydroxysteroid dehydrogenase ( $3 \beta-\mathrm{HSD})$, cytochrome $\mathrm{P} 450 \mathrm{c}_{17}$, 
21-hydroxylase (cytochrome P450c21), 11ß-hydroxylase (cytochrome P45011 $\beta$ ) and cytochrome P450 aldosterone synthetase (P-450aldo).

$3 \beta$-Hydroxysteroid dehydrogenase catalyzes the conversion of $\Delta^{5}$-3 $\beta$-hydroxysteroids into $\Delta^{4}$-3-ketosteroids (i.e. the conversion of pregnenolone into progesterone). Cytochrome $\mathrm{P} 450 \mathrm{c}_{17}$, possessing both $17 \alpha$-hydroxylase and 17,20 lyase activity, is responsible for the conversion of $\mathrm{C}_{21}$ steroids (pregnenolone, progesterone) into $\mathrm{C}_{19}$ steroids (dehydroepiandrosterone (DHEA) and androstenedione).

21-Hydroxylase converts progesterone to 11-deoxycorticosterone and 17-hydroxyprogesterone to 11deoxycortisol, the substrates required for the production of the main adrenal steroids, corticosterone, aldosterone and cortisol.

$11 \beta$-Hydroxylase (cytochrome P45011 $\beta$ ) catalyzes the formation of glucocorticoids (cortisol and corticosterone). Cytochrome $\mathrm{P} 450$ aldosterone synthetase (P-450aldo), which exerts three enzyme activities (11ß-hydroxylation, 18-hydroxylation, and 18-oxidoreduction), catalyzes the formation of mineralocorticoids (aldosterone).

Studies on the expression of 21-hydroxylase in the brain are scarce. In rodents, 21-hydroxylase was detected in the brain stem using the reverse transcription-polymerase chain reaction assay and immunohistochemical methods $(76,77)$, whereas other investigators could not find 21-hydroxylase mRNA in any extra-adrenal tissue (78). As this may be due to the limited sensitivity of the mRNA quantification assay, we investigated the expression of 21-hydroxylase mRNA in the human hippocampus using a highly sensitive nested RT-PCR assay (79). This study was the first to demonstrate that 21-hydroxylase mRNA is expressed in the human hippocampus. The expression levels in the hippocampus are approximately 10000 times lower than in the adrenal gland which is known for high 21hydroxylase expression (79). However, we could not measure the enzyme activity of 21-hydroxylase since only small amounts of tissue specimens were available. Thus, although our results clearly demonstrate that 21-hydroxylase mRNA is expressed in small amounts in the human hippocampus, it remains debatable whether hippocampal tissue contains sufficient 21-hydroxylase to produce neuroactive steroid concentrations of physiological or pathophysiological relevance.

The mRNAs of $3 \beta$-HSD 1 and 2 as well as cytochrome $\mathrm{P} 45011 \beta$ and cytochrome $\mathrm{P} 450$ aldosterone synthetase were not expressed in the human temporal lobe nor in the hippocampus (own unpublished data). A sensitive, nested competitive RT-PCR assay was used for these investigations. However, several studies demonstrated the expression of $3 \beta$-HSD mRNA $(21,80,81)$ and $3 \beta$-HSD protein $(81)$ in the rat brain. Data concerning the expression of cytochrome $\mathrm{P} 45011 \beta$ in rodent brain are conflicting: while some authors report the expression throughout the rat brain
$(77,82)$, others found only low expression levels in rat brain $(17,83)$ or no expression in mouse brain $(77)$. Cytochrome P450 aldosterone synthetase expression and activity has been demonstrated in various regions of rat brain including hypothalamus, hippocampus, amygdala and cerebellum $(82,84)$.

Cytochrome P450c $\mathrm{c}_{17}$ mRNA was not expressed in the human temporal lobe or hippocampus (own unpublished data). Former studies failed to demonstrate $17 \alpha$-hydroxylase activity or P450c17 mRNA in the adult rat brain $(6,17)$. However, using ribonuclease protection assays and immunocytochemistry, P450c17 mRNA as well as P450c17 protein were detected in the brain of rat embryos (85). Conflicting data have been reported in adults: Compagnone and co-workers (85) reported expression of P450c17 mRNA only in the peripheral nervous system of rats and mice, whereas others demonstrated the presence of P450c17 mRNA in various brain regions of adult rodents (77).

\section{Clinical implications}

Molecular biological and biochemical studies have now firmly established the presence of the above mentioned steroidogenic enzymes cytochrome $\mathrm{P} 450_{\mathrm{SCC}}$, aromatase, $5 \alpha$-reductase, $3 \alpha$-hydroxysteroid dehydrogenase and $17 \beta$-hydroxysteroid dehydrogenase in human brain and provide evidence that neurosteroids and neuroactive steroids can be produced within the human brain. However, the (patho)physiological significance of these findings remains to be elucidated. Fig. 1 and Table 1 present a summary of current knowledge and open questions on biochemical pathways of steroid metabolism in the human brain.

Steroid hormone effects on the brain have typically been associated with gene regulation via intracellular steroid receptors. In contrast to reproductive and neuroendocrine actions of steroids via these intracellular receptors, which regulate transcriptionally directed changes in protein synthesis, modulatory actions on the GABA receptor system can rapidly alter the excitability of neurons $(7,8)$. GABA, a major inhibitory neurotransmitter, mediates fast synaptic inhibition by activating ligand-gated chloride channels. Binding of $3 \alpha$-reduced neurosteroids to $\mathrm{GABA}_{\mathrm{A}}$ receptors leads to either inhibition or potentiation of the inhibitory effects of GABA. Hence, anticonvulsive, anesthetic and anxiolytic effects of neuroactive steroids are mediated by their capacity to positively modulate $\mathrm{GABA}_{\mathrm{A}}$ receptor function, i.e. these substances act to increase GABA-ergic effects by increasing the frequency and duration of chloride channel openings $(7$, 8). On the other hand, inhibition of $\mathrm{GABA}_{\mathrm{A}}$ receptor function which is mostly documented for the neurosteroids pregenenolone sulfate and DHEA sulfate (DHEAS) produces effects ranging from anxiety and excitability to seizure susceptibility $(9,11,12)$. However, there is strong evidence for a putative specific 


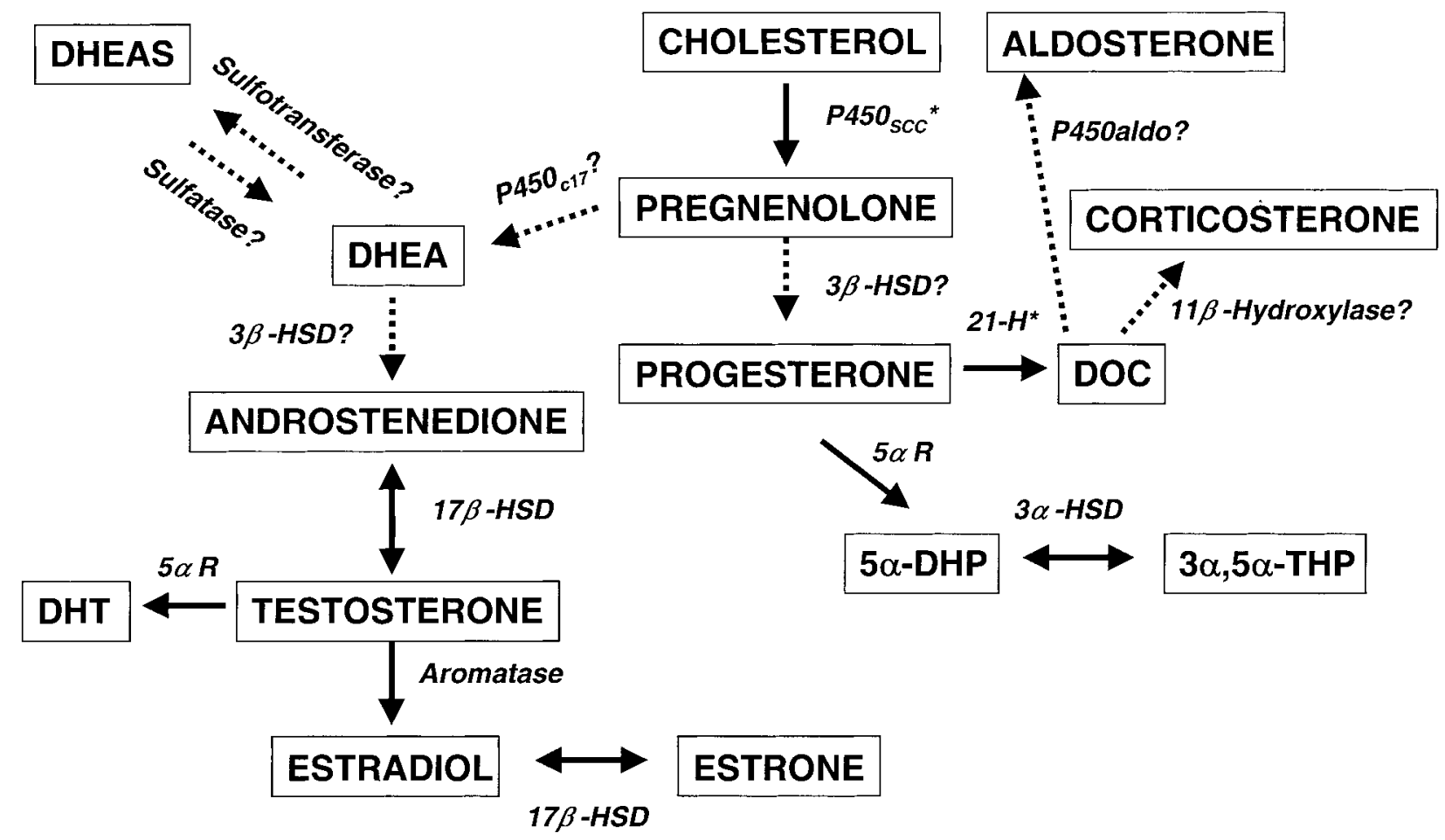

Figure 1 Current knowledge and open questions concerning the biochemical pathways of neurosteroidogenesis in the human brain. Solid arrows indicate that the activity of the respective enzyme as well as the expression of its mRNA has been documented with the exception of $\mathrm{P}^{4} \mathrm{~S}_{\mathrm{scc}}$ and 21-hydroxylase (marked by an asterisk) as here only the expression of its mRNA has been shown. Dashed arrows indicate that the occurrence of the enzyme has not yet been found in the nervous system. DOC, deoxycorticosterone; DHT, dihydrotestosterone; $5 \alpha$-DHP, $5 \alpha$-dihydroprogesterone; $3 \alpha, 5 \alpha$-THP, $3 \alpha, 5 \alpha$-tetrahydroprogesterone (allopregnanolone); $5 \alpha \mathrm{R}$, $5 \alpha$-reductase; $3 \alpha$-HSD, $3 \alpha$-hydroxysteroid oxidoreductase; $3 \beta-H S D, 3 \beta$-hydroxysteroid oxidoreductase; $17 \beta-H S D$, $17 \beta$-hydroxysteroid dehydrogenase; $21-\mathrm{H}, 21$-hydroxylase.

steroid binding site at the $\mathrm{GABA}_{\mathrm{A}}$ receptor (86). In addition, other neurosteroid actions have been described in the brain including the inhibition of voltage-gated $\mathrm{Ca}^{2+}$ currents and NMDA receptor function as well as the modulation of other receptors, such as nicotinic, muscarinic, serotonin $\left(5-\mathrm{HT}_{3}\right)$, kainate, glycine and sigma receptors (13, 86-90). Moreover, it has been postulated that neurosteroids act on nerve cells through membrane receptors coupled to $\mathrm{G}$ proteins (91) and may also interact with various neuropeptide receptors (92). There is also evidence that neurosteroids may regulate gene expression by activating progesterone receptors $(86,93)$. In addition, other steroid effects apart from the modulation of neurotransmitter receptors have emerged: for example, estrogen might serve as a neuroprotective antioxidant (94). In summary, neurosteroids exert both genomic and nongenomic effects, and regulate neuronal function via their concurrent influence on gene expression and transmitter-gated ion channels. These actions

Table 1 Expression of mRNA and activity of steroidogenic enzymes in the human brain.

\begin{tabular}{lccl}
\hline Enzyme & mRNA expression & Enzyme activity & Reference \\
\hline Cytochrome P450scc & + & $?$ & 19,20 \\
21-Hydroxylase & + & $?$ & 79 \\
Cytochrome P450 aromatase & + & + & $26-33,41$ \\
$5 \alpha$-Reductase type 1 & + & + & $46-53 ; 56$ \\
$3 \alpha$-Hydroxysteroid dehydrogenase type 2 & + & $?$ & 52,56 \\
3 $\alpha$-Hydroxysteroid dehydrogenase type 3 & + & $?$ & 64 \\
$17 \beta$-Hydroxysteroid dehydrogenase type 1 & + & + & 73 \\
$17 \beta$-Hydroxysteroid dehydrogenase type 3 & + & + & 73,75 \\
$17 \beta$-Hydroxysteroid dehydrogenase type 4 & + & $?$ & 73,75 \\
$17 \beta$-Hydroxysteroid dehydrogenase type 5 & + & +44 \\
\hline
\end{tabular}

+ , Expression or activity has been demonstrated. 
suggest that neurosteroids play a crucial role in mediating many brain functions. Moreover, the systemic effects of neurosteroids may be beneficial for a variety of neuropsychiatric disorders.

To date, the majority of physiological and behavioral studies have been carried out in rodents or other animal species. In recent years, evidence for an intensive neurosteroid metabolism within the human brain has emerged and now the first clinical investigations exist to support the results obtained in preclinical animal studies.

The potential anesthetic properties of neurosteroids had already been suggested in 1941 (10), and have led to the development of steroid anesthetics, e.g. alphaxalone (95). However, side effects have hindered the development of steroid anesthetics for routine clinical use (9).

The observation that epileptic seizures in cyclic women are less frequent in the luteal phase, when circulating levels of progesterone are high, appears to be associated with cyclical variations in the metabolism of progesterone to allopregnanolone in the brain $(8,96$, 97). Progesterone and $3 \alpha$-reduced neuroactive steroids have potent anticonvulsant effects $(98,99)$. Synthetic derivates of neuroactive steroids are under investigation for treatment of epilepsy disorders. Some preliminary investigations in healthy volunteers and in patients with medically intractable epilepsies have already been undertaken. Ganaxolone, for example, showed a promising pharmaco-kinetic profile and was well tolerated in a trial with healthy volunteers (100, 101). It was also effective in clinical studies with patients with epilepsy (102). Although promising, caution is necessary considering the potential side effects. For example, progesterone and $3 \alpha, 5 \alpha$-THP have benzodiazepine-like effects $(98,99)$, and progesterone withdrawal may lead to an increase in seizure susceptibility.

The development of sensitive assays to measure cerebral fluid or blood neurosteroid concentrations enabled researchers to document alterations in neurosteroidogenesis in human diseases. Recently, Ströhle and co-workers demonstrated decreased $3 \alpha, 5 \alpha$-tetrahydroprogesterone plasma concentrations in patients with major depression compared with healthy control subjects, and clinically effective antidepressant treatment was accompanied by an increase of $3 \alpha, 5 \alpha-$ tetrahydroprogesterone in the plasma of these patients (103).

Substances which activate the $\mathrm{GABA}_{\mathrm{A}}$ receptor exert anxiolytic effects. Benzodiazepines and barbiturates are the most widely used anxiolytics in medicine. The GABA agonistic $3 \alpha$-reduced neuroactive steroids may have a potential advantage as anxiolytics in comparison to benzodiazepines because of their more favorable tolerance and abuse liability profile in various drug discrimination paradigms (104). However, whether the anxiolytic properties of $3 \alpha$-reduced neuroactive steroids suggested by animal studies can be confirmed in clinical trials with human beings is still a matter of speculation.

Neuroactive steroids may also be involved in physiological conditions where fluctuations of the hormonal balance occur. For example, increased fatigue during pregnancy may be a consequence of higher concentrations of progesterone and GABA agonistic $3 \alpha$-reduced neuroactive steroids like $3 \alpha, 5 \alpha$ THP (105), whereas a rapid decline in these substances may lead to the premenstrual syndrome or post partum depression $(106,107)$. In rats, others have related endogenous $3 \alpha, 5 \alpha$-THP synthesis/metabolism rate during pregnancy with changes in $\mathrm{GABA}_{\mathrm{A}}$ receptor subunits (108), suggesting that the pharmacological changes in $\mathrm{GABA}_{\mathrm{A}}$ receptor subunits and their associated behavior are regulated by local production of $3 \alpha, 5 \alpha$-THP. Using a pseudopregnant rat model, Smith and co-workers (109) showed that withdrawal of $3 \alpha, 5 \alpha$-THP caused a relative insensitivity of $\mathrm{GABA}_{\mathrm{A}}$ to neurosteroid neuromodulation, and induced increased anxiety. Moreover, fluctuations in neuroactive steroid concentrations may, in part, contribute to the increased risk of developing psychiatric diseases in women at the perimenstrual phase, during pregnancy and the post partum period, and around menopause.

In alcoholic patients, reduced plasma concentrations of GABA agonistic $3 \alpha$-reduced neuroactive steroids have been found during ethanol withdrawal (110). This decline in $3 \alpha$-reduced neuroactive steroid concentrations may contribute to the increased seizure liability during ethanol withdrawal.

In humans, DHEA and DHEAS are the most abundant circulating steroid hormones and their concentrations decrease with age (111). Stress also decreases DHEA and DHEAS concentrations (112). As both age and stress are associated with neuronal vulnerability to degeneration, it was hypothezised that DHEA and DHEAS may be neuroprotective agents. Indeed, neuroprotection by DHEA and DHEAS was observed in vivo in hippocampal structures (113). The mechanisms by which DHEA and DHEAS act are still unknown. Decreased DHEAS concentrations have also been reported in patients with Alzheimer's disease and multi-infarct dementia (114-116). To date, trials in which DHEA was administered for a short period of two weeks have failed to demonstrate any benefit of DHEA therapy in cognitive performance (117-119). However, high-quality trials need to be undertaken in which the duration of DHEA treatment is in excess of a few weeks with a large enough number of participants to detect possible effects and where the outcome measures include objective tests of cognitive function.

In recent years, a great deal of research has focused on the effects of sex hormones on cognitive functions in humans. Perhaps the most prominent examples are the effects of estrogens and androgens on verbal fluency, the performance of spatial tasks, verbal memory tests 
and fine-motor skills (120-122). The hormonal influences on memory processes appear to involve actions in brain structures such as the hippocampus and basal forebrain. There is now considerable documentation of estrogenic influences on hippocampal morphology and neurochemistry including the enhancement of the cholinergic system, which is involved in learning and memory (for reviews see: 123-127). Estrogens exert neurotropic and neuroprotective effects such as induction of neurite outgrowth, dendritic spines, and synaptogenesis. They have an influence on long-term potentiation and excitability, enhance gene expression and exhibit intrinsic antioxidant activity. Verbal fluency, memory, fine motor skills and the performance of spatial tasks are all subject to sex-specific differences. Thus, estrogen effects differ quantitatively or qualitatively between the sexes. Sex-specific differences also have an effect on the incidence of psychopathologies such as anxiety disorders, depression and migraine, which are more common in females, whereas substance abuse, antisocial behavior as well as pain sensitivity are more common in males. Estrogen replacement therapy has beneficial effects on verbal memory tests in surgically postmenopausal women (121). Alzheimer's disease occurs more frequently in elderly women than in elderly men (128), and there seems to be a possible link between estrogen deficiency and dementia. One study revealed a significant reduction in Alzheimer's disease as a cause of death in women who had taken estrogens postmenopausally, with an apparently greater protective effect resulting from higher dosage and longer exposure (128). Nevertheless, the authors have pointed out the need for prospective randomized treatment trials to substantiate the beneficial effects of estrogen replacement therapy. Although testosterone levels in elderly men decrease with age, production never ceases completely so that the prohormone for the production of estradiol exists in men throughout their life time. As the human brain contains aromatase, which is necessary for the conversion of testosterone to estradiol, estradiol is available to the brains of men throughout their life, whereas it is not available to the brains of untreated postmenopausal women.

\section{Conclusions}

Molecular biological and biochemical studies have now firmly established that several key enzymes of steroidogenesis, namely cytochrome $\mathrm{P} 450_{\mathrm{Scc}}$, aromatase, $5 \alpha-$ reductase, $3 \alpha$-hydroxysteroid dehydrogenase and $17 \beta$-hydroxysteroid dehydrogenase, are present in human brain (Fig. 1, Table 1). Their presence in the cerebral cortex and in the subcortical white matter indicates that various cell types, either neurons or glial cells, are involved in the biosynthesis of neurosteroids and neuroactive steroids in the brain. We still do not know whether and how the steroidogenic enzymes are involved in the pathophysiology of the nervous system. However, clinical investigations in humans are now producing evidence for an involvement of neuroactive steroids in conditions such as fatigue during pregnancy, premenstrual syndrome, post partum depression, catamenial epilepsy, depressive disorders and dementia disorders. Results from preclinical and clinical studies strongly support the hypothesis that neuroactive steroids could be useful for therapeutic management of such disorders in the future.

\section{References}

1 Martini L \& Melcangi RC. Androgen metabolism in the brain. Journal of Steroid Biochemistry and Molecular Biology 199139 819-828.

2 Lephart ED. Brain 5 $\alpha$-reductase: cellular, enzymatic, and molecular perspectives and implications for biological function. Molecular and Cellular Neurosciences 19934 473-484.

3 Naftolin F. Brain aromatization of androgens. Journal of Reproductive Medicine 199439 257-261.

4 Robel P, Schumacher M \& Baulieu EE. Neurosteroids: from definition and biochemistry to physiopathologic function. In Neurosteroids. A New Regulatory Function in the Nervous System, edn 1, ch 1, pp 1-25. Eds E E Baulieu, P Robel \& M Schumacher. Totowa, New Jersey: Humana Press, 1999.

5 Naftolin F, Ryan KJ, Davies IJ, Reddy VV, Flores F, Petro Z et al. The formation of estrogens by central neuroendocrine tissues. Recent Progress in Hormone Research 197531 295-319.

6 Baulieu EE \& Robel P. Neurosteroids: a new brain function? Journal of Steroid Biochemistry and Molecular Biology 199037 395-403.

7 Majewska MD. Neurosteroids: endogenous bimodal modulators of the $\mathrm{GABA}_{\mathrm{A}}$ receptor. Mechanism of action and physiological significance. Progress in Neurobiology 199238 379-395.

8 Mellon S. Neurosteroids: biochemistry, modes of action, and clinical relevance. Journal of Clinical Endocrinology and Metabolism 199478 1003-1008.

9 Paul SM \& Purdy RH. Neuroactive steroids. FASEB Journal $199262311-2322$.

10 Selye $H$. The anesthetic effect of steroid hormones. Proceedings of the Society of Experimental Biology and Medicine 194146 116-121.

11 Baulieu EE. Neurosteroids: of the nervous system, by the nervous system, for the nervous system. Recent Progress in Hormone Research 199752 1-33.

12 Baulieu EE. Neurosteroids: a novel function of the brain. Psychoneuroendocrinology 199823 963-987.

13 Mensah-Nyagan A, Do-Rego JL, Beaujean D, Luu-The V, Pelletier G \& Vaudry H. Neurosteroids: expression of steroidogenic enzymes and regulation of steroid biosynthesis in the central nervous system. Pharmacological Reviews 199951 63-81.

14 Chung BC, Matteson KJ, Voutilainen R, Mohandas TK \& Miller WL. Human cholesterol side-chain cleavage enzyme, P450SCC: cDNA cloning, assignment of the gene to chromosome 15, and expression in the placenta. PNAS $1986 \mathbf{8 3}$ 8962-8966.

15 Simpson ER \& MacDonald PC. Endocrine physiology of the placenta. Annual Review of Physiology 198143 163-188.

16 Keeney DS, Ikeda Y, Waterman MR \& Parker KL. Cholesterol side-chain cleavage cytochrome $\mathrm{P} 450$ gene expression in the primitive gut of the mouse embryo does not require steroidogenic factor 1. Molecular Endocrinology $1995 \mathbf{9}$ 1091-1098.

17 Mellon S \& Deschepper CF. Neurosteroid biosynthesis: genes for adrenal steroidogenic enzymes are expressed in the brain. Brain Research 1993629 283-292. 
18 Warner M \& Gustafsson J-A. Cytochrome P450 in the brain: neuroendocrine functions. Frontiers in Neuroendocrinology 1995 $16224-236$.

19 Watzka M, Bidlingmaier F, Schramm J, Klingmüller D \& StoffelWagner B. Sex- and age-specific differences in human brain CYP11A1 mRNA expression. Journal of Neuroendocrinology $199911901-905$.

20 Beyenburg S, Stoffel-Wagner B, Watzka M, Blümcke I, Bauer J, Schramm J et al. Expression of cytochrome P450scc mRNA in the hippocampus of patients with temporal lobe epilepsy. NeuroReport 199910 3067-3070.

21 Sanne JL \& Krueger KE. Expression of cytochrome P450 sidechain cleavage enzyme and 3beta-hydroxysteroid dehydrogenase in the rat central nervous system: a study by polymerase chain reaction and in situ hybridization. Journal of Neurochemistry $1995 \mathbf{6 5} 528-536$.

22 Kohchi C, Ukena K \& Tsutsui K. Age- and region-specific expressions of the messenger RNAs encoding for steroidogenic enzymes p450SCC, p450c17 and 3beta-HSD in the postnatal rat brain. Brain Research $1998 \mathbf{8 0 1} 233-238$.

$23 \mathrm{Hu}$ ZY, Bourreau E, Jung-Testas I, Robel P \& Baulieu E-E. Neurosteroids: oligodendrocyte mitochondria convert cholesterol to pregnenolone. PNAS $1987 \mathbf{8 4} 8215-8219$.

24 Corbin JC, Graham-Lorence S, McPhaul MJ, Mason JI, Mendelson CR \& Simpson ER. Isolation of a full-length cDNA insert encoding human aromatase system cytochrome P-450 and its expression in non-steroidogenic cells. PNAS $1988 \mathbf{8 5}$ 8948-8953.

25 Harada N. Cloning of a comparative cDNA encoding human aromatase: immunochemical identification and sequence analysis. Biochemical and Biophysical Research Communications $1988156725-732$.

26 Naftolin F, Ryan KJ \& Petro Z. Aromatization of androstenedione by the diencephalon. Journal of Clinical Endocrinology and Metabolism 197133 368-370.

27 Naftolin F, Ryan KJ \& Petro Z. Aromatization of androstenedione by limbic system tissue from human foetuses. Journal of Endocrinology 197151 795-796.

28 Doody KJ \& Carr BR. Aromatase in human fetal tissues. American Journal of Obstetrics and Gynecology $19891611694-$ 1697.

29 Wozniak A, Hutchinson RE, Morris CM \& Hutchinson JB. Neuroblastoma and Alzheimer's disease brain cells contain aromatase activity. Steroids 199863 263-267.

30 Stoffel-Wagner B, Watzka M, Schramm J, Bidlingmaier F \& Klingmüller D. Expression of CYP19 (aromatase) mRNA in different areas of the human brain. Journal of Steroid Biochemistry and Molecular Biology 1999 70 237-241.

31 Stoffel-Wagner B, Watzka M, Steckelbroeck S, Schwaab R, Schramm J, Bidlingmaier $\mathrm{F}$ et al. Expression of CYP19 (aromatase) mRNA in the human temporal lobe. Biochemical and Biophysical Research Communications 1998244 768-771.

32 Steckelbroeck S, Heidrich D, Stoffel-Wagner B, Hans VHJ, Schramm J, Bidlingmaier $\mathrm{F}$ et al. Characterization of aromatase cytochrome P450 activity in the human temporal lobe. Journal of Clinical Endocrinology and Metabolism $1999 \mathbf{8 4} 2795-2801$.

33 Henderson D, Norbisrath G \& Kerb U. 1-Methyl-1, 4androstandiene-3,17-dione (SH 489): characterization of an irreversible inhibitor of estrogen biosynthesis. Journal of Steroid Biochemistry 198624 303-306.

34 Ackerman GE, Smith ME, Mendelson CR, MacDonald PC \& Simpson ER. Aromatization of androstenedione by human adipose tissue stromal cells in monolayer culture. Journal of Clinical Endocrinology and Metabolism 198153 412-417.

35 Rowlands MG, Davies JH, Shearer RJ \& Dowsett M. Comparison of aromatase activity in human prostatic, testicular and placental tissues. Journal of Enzyme Inhibition 19914 307-313.

36 Mahendroo MS, Means GD, Mendelson CR \& Simpson ER. Tissue-specific expression of human P450arom: the promotor responsible for expression in adipose tissue is different from that utilized in placenta. Journal of Biological Chemistry 1991266 11276-11281.

37 Means GD, Kilgore MW, Mahendroo MS, Mendelson CR \& Simpson ER. Tissue-specific promotors regulate aromatase cytochrome P450 gene expression in human ovary and fetal tissues. Molecular Endocrinology 19915 2005-2013.

38 Bulun SE, Rosenthal IM, Brodie AM, Inkster SE, Zeller WP, DiGeorge AM et al. Use of tissue-specific promotors in the regulation of aromatase cytochrome P450 gene expression in human testicular and ovarian sex cord tumors, as well as in normal fetal and adult gonads. Journal of Clinical Endocrinology and Metabolism 199377 1616-1621.

39 Harada N, Utsumi T \& Takagi Y. Tissue-specific expression of the human aromatase cytochrome p-450 gene by alternative of tissue-specific exons 1 in carcinogenesis. PNAS $1993 \mathbf{9 0}$ 11312-11316.

40 Honda S, Harada N \& Tagaki Y. Novel exon 1 of the aromatase gene specific for aromatase transcripts in human brain. Biochemical and Biophysical Research Communications 1994 198 1153-1160.

41 Sasano H, Takahashi K, Satoh F, Nagura H \& Harada N. Aromatase in the human central nervous system. Clinical Endocrinology $1998 \mathbf{4 8} 325-329$.

42 Andersson S \& Russell DW. Structural and biochemical properties of cloned and expressed human and rat steroid $5 \alpha$ reductases. PNAS $1990 \mathbf{8 7}$ 3640-3644.

43 Andersson S, Berman DM, Jenkins EP \& Russell DW. Deletion of steroid $5 \alpha$-reductase 2 gene in male pseudohermaphroditism. Nature 1991354 159-161.

44 Martini L. The $5 \alpha$-reduction of testosterone in the neuroendocrine structures. Biochemical and physiological implications. Endocrine Reviews $198231-25$.

$45 \mathrm{Li} \mathrm{X}$, Bertics PJ \& Karavolas HJ. Regional distribution of cytosolic and particulate $5 \alpha$-dihydroprogesterone $3 \alpha$-hydroxysteroid oxidoreductases in female rat brain. Journal of Steroid Biochemistry and Molecular Biology 199760 311-318.

46 Saitoh H, Hirato K, Yanaihara T \& Nakayama T. A study of $5 \alpha-$ reductase in human fetal brain. Endocrinologica Japonica 1982 29 461-467.

47 Schindler AE. Steroid metabolism in foetal tissues-IV. Conversion of testosterone to $5 \alpha$-dihydrotestosterone in human foetal brain. Journal of Steroid Biochemistry 1976 7 97-100.

48 Mickan H. Metabolism of 4-14C-progesterone and 4-14-Ctestosterone in brain of the previable human fetus. Steroids $197219659-668$.

49 Jenkins JS \& Hall CJ. Metabolism of $\left[{ }^{14} \mathrm{C}\right]$ testosterone by human foetal and adult brain tissue. Journal of Endocrinology $1977 \mathbf{7 4}$ 425-429.

50 Celotti F, Melcangi RC, Negri-Cesi P, Ballabio M \& Martini L. A comparative study of the metabolism of testosterone in the neuroendocrine structures of several animal species. Neuroendocrinology Letters $19865227-236$.

51 Stoffel-Wagner B, Watzka M, Steckelbroeck S, Wickert L, Schramm J, Romalo G et al. Expression of $5 \alpha$-reductase in the human temporal lobe of children and adults. Journal of Clinical Endocrinology and Metabolism 199883 3636-3642.

52 Stoffel-Wagner B, Beyenburg S, Watzka M, Blümcke I, Bauer J, Schramm J et al. Expression of $5 \alpha$-reductase and $3 \alpha$ hydroxysteroid oxidoreductase in the hippocampus of patients with chronic temporal lobe epilepsy. Epilepsia $2000 \mathbf{4 1} 140$ 147.

53 Thigpen AE, Silver RI, Guileyardo JM, Casey ML, McConnell JD \& Russell DW. Tissue distribution and ontogeny of steroid $5 \alpha-$ reductase isoenzyme expression. Journal of Clinical Investigation 199392 903-910.

54 Normington K \& Russell DW. Tissue distribution and kinetic characteristics of rat steroid $5 \alpha$-reductase isozymes. Journal of Biological Chemistry 1992267 19548-19554.

55 Poletti A, Negri-Cesi P, Rabuffetti M, Colciago A, Celotti F \& Martini L. Transient expression of the $5 \alpha$-reductase type 2 
isozyme in the rat brain in the late fetal and early postnatal life. Endocrinology 1998139 2171-2178.

56 Steckelbroeck S, Watzka M, Reichelt R, Hans VHJ, StoffelWagner B, Heidrich DD et al. Characterization of the $5 \alpha$ reductase- $3 \alpha$-hydroxysteroid dehydrogenase complex in the human brain. Journal of Clinical Endocrinology and Metabolism 200186 1324-1331.

57 Resko JA, Connolly PB \& Roselli CE. Testosterone $5 \alpha$-reductase activity in neural tissue of fetal rhesus macaques. Journal of Steroid Biochemistry 198829 429-434.

58 Massa R, Justo S \& Martini L. Conversion of testosterone into $5 \alpha$-reduced metabolites in the anterior pituitary and in the brain of maturing rats. Journal of Steroid Biochemistry 197519 235-239.

59 Selmanoff MK, Brodkin LD, Weiner RI \& Siiteri PK. Aromatization and $5 \alpha$-reduction of androgens in discrete hypothalamic and limbic regions of the male and female rat. Endocrinology $1977101841-848$

60 Qin KN, New MI \& Cheng KC. Molecular cloning of multiple cDNAs encoding human enzymes structurally related to $3 \alpha-$ hydroxysteroid dehydrogenase. Journal of Steroid Biochemistry and Molecular Biology 199352 141-147.

61 Khanna M, Qin K-N, Wang RW \& Cheng K-C. Substrate specificity, gene structure, and tissue-specific distribution of multiple human $3 \alpha$-hydroxysteroid dehydrogenases. Journal of Biological Chemistry $199527020162-20168$.

62 Khanna M, Qin KN \& Cheng K-C. Distribution of 3alphahydroxysteroid dehydrogenase in rat brain and molecular cloning of multiple cDNAs encoding structurally related proteins in humans. Journal of Steroid Biochemistry and Molecular Biology 199553 41-46.

63 Penning TM. Molecular endocrinology of hydroxysteroid dehydrogenases. Endocrine Reviews 199718 281-305.

64 Penning TM, Burczynski ME, Jez JM, Hung CF, Lin HK, Ma H et al. Human 3 $\alpha$-hydroxysteroid dehydrogenase isoforms (AKR1C1-AKR1C4) of the aldo-keto reductase superfamily: functional plasticity and tissue distribution reveals roles in the inactivation and formation of male and female sex hormones. Biochemical Journal $200035167-77$.

65 Russell DW \& Wilson JD. Steroid $5 \alpha$-reductase: two genes, two enzymes. Annual Reviews of Biochemistry $19946315266-$ 15272.

66 Cheng K-C, Lee J, Khanna M \& Qin K-N. Distribution and ontogeny of $3 \alpha$-hydroxysteroid dehydrogenase in the rat brain. Journal of Steroid Biochemistry and Molecular Biology 199450 85-89.

67 Peltoketo H, Luu-The V, Simard J \& Adamski J. 17ßHydroxysteroid dehydrogenase (HSD)/17-ketosteroid reductase (KSR) familiy; nomenclature and main characteristics of the 17HSD/KSR enzymes. Journal of Molecular Endocrinology 1999 $231-11$.

68 Krazeisen A, Breitling R, Imai K, Fritz S, Möller G \& Adamski J. Determination of cDNA, gene structure and chromosomal localization of the novel $17 \beta$-hyxdroxysteroid dehydrogenase type 7. FEBS Letters $1999 \mathbf{4 6 0} 373-379$.

69 Labrie F, Luu-The V, Lin SX, Labrie C, Simard J, Breton R et al. A key role of $17 \beta$-hydroxysteroid dehydrogenases in sex steroid biology. Steroids 199762 148-158.

70 Martel C, Melner MH, Gagné D, Simard J \& Labrie F. Widespread tissue distribution of steroid sulfatase, $3 \beta$-hydroxysteroid

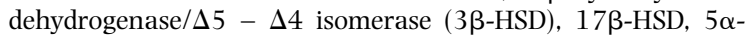
reductase and aromatase activities in the rhesus monkey. Molecular and Cellular Endocrinology 1994104 103-111.

71 Jaffe RB. Testosterone metabolism in target tissues: hypothalamic and pituitary tissues of the adult rat and human fetus, and the immature rat epiphysis. Steroids 1969 14 483-498.

72 Milewich L, Carr BR, Frenkel RA, Marrero M, MacDonald PC \& Mason JI. 17ß-Hydroxysteroid oxidoreductases of human fetal and adult tissues: immunological cross-reactivity with an antihuman placental cytosolic $17 \beta$-hydroxysteroid oxidoreductase antibody. Placenta 199011 95-108.
73 Stoffel-Wagner B, Watzka M, Steckelbroeck S, Schramm J, Bidlingmaier F \& Klingmüller D. Expression of $17 \beta$-hydroxysteroid dehydrogenase types $1,2,3$ and 4 in the human temporal lobe. Journal of Endocrinology 1999160 119-126.

74 Steckelbroeck S, Watzka M, Stoffel-Wagner B, Hans VHJ, Clusmann H, Elger CE et al. Expression of 17ß-hydroxysteroid dehydrogenase type 5 mRNA in the human brain. Molecular and Cellular Endocrinology 2001171 165-168.

75 Steckelbroeck S, Stoffel-Wagner B, Reichelt R, Schramm J, Bidlingmaier F, Siekmann L et al. Characterization of $17 \beta-$ hydroxysteroid dehydrogenase activity in brain tissue: testosterone formation in the human temporal lobe. Journal of Neuroendocrinology 199911 457-464.

76 Iwahashi K, Kawai Y, Suwaki H, Hosokawa K \& Ichikawa Y. A localization study of the cytochrome P-450(21)-linked monooxygenase system in adult rat brain. Journal of Steroid Biochemistry and Molecular Biology 199344 163-169.

77 Stromstedt M \& Waterman MR. Messenger mRNAs encoding steroidogenic enzymes are expressed in rodent brain. Brain Research. Molecular Brain Research 199534 75-88.

78 Mellon SH \& Miller WL. Extraadrenal steroid 21-hydroxylation is not mediated by P450c21. Journal of Clinical Investigation 198984 1497-1502.

79 Beyenburg S, Watzka M, Clusmann $\mathrm{H}$, Blümcke I, Bidlingmaier F, Elger CE et al. Messenger RNA of steroid 21hydroxylase (CYP21) is expressed in the human hippocampus. Neuroscience Letters 2001308 111-114.

80 Dupont E, Simard J, Luu-The V, Labrie F \& Pelletier G. Localization of 3beta-hydroxysteroid dehydrogenase in rat brain as studied by in situ hybridization. Molecular and Cellular Neurosciences 19945 119-123.

81 Guennoun R, Fiddes RJ, Gouézou M, Lombès M \& Baulieu EE. A key enzyme in the biosynthesis of neurosteroids, $3 \beta$-hydroxysteroid dehydrogenase/ $\Delta 5-\Delta 4$-isomerase ( $3 \beta$-HSD), is expressed in rat brain. Molecular Brain Research 199530 287-300.

82 Gomez-Sanchez CE, Zhou MY, Cozza EN, Morita H, Eddleman FC \& Gomez-Sanchez EP. Corticoid synthesis in the central nervous system. Endocrine Research 199622 463-470.

83 Erdmann B, Gerst H, Lippoldt A, Bulow H, Ganten D, Fuxe K et al. Expression of cytochrome P45011B1 mRNA in the brain of normal and hypertensive transgenic rats. Brain Research $199673373-82$

84 Gomez-Sanchez CE, Zhou MY, Cozza EN, Morita H, Foecking MF \& Gomez-Sanchez EP. Aldosterone biosynthesis in the rat brain. Endocrinology 1997138 3369-3373.

85 Compagnone NA, Bufone A, Rubenstein JLR \& Mellon SH. Steroidogenic enzyme P450c17 is expressed in the embryonic central nervous system. Endocrinology $19951365212-5223$.

86 Rupprecht R \& Holsboer F. Neuroactive steroids: mechanism of action and neuropsychopharmacological perspectives. Trends in Neurosciences 199922 410-416.

87 Wu FS, Gibbs TT \& Farb DH. Pregnenolone sulfate: a positive allosteric modulator at the N-methyl-D-aspartate receptor. Molecular Pharmacology 199140 333-336.

88 Prince RJ \& Simmonds MA. Steroid modulation of the strychnine-sensitive glycine receptor. Neuropharmacology 1992 31 201-205.

89 Monnet FP, Mahé V, Robel P \& Baulieu EE. Neurosteroids, via $\sigma$ receptors modulate the $\left[{ }^{3} \mathrm{H}\right]$ norepinephrine release evoked by N-methyl-D-aspartate in the rat hippocampus. PNAS 199592 3774-3778.

90 Lambert JJ, Belelli D, Hill-Venning C \& Peters JA. Neurosteroids and GABA A receptor function. Trends in Pharmacological Sciences $199516295-303$.

91 Orchinik M, Murray TF, Franklin PH \& Moore FL. Guanyl nucleotides modulate binding to steroid receptors in neuronal membranes. PNAS 199289 3830-3834.

92 Grazzini E, Guillon G, Mouillac B \& Zingg HH. Inhibition of oxytocin receptor function by direct binding of progesterone. Nature 1998392 509-512. 
93 Rupprecht R, Reul JM, Trapp T, van Steensel B, Wetzel C, Damm K et al. Progesterone receptor-mediated effects of neuroactive steroids. Neuron 199311 523-530.

94 Behl C \& Holsboer F. The female sex hormone oestrogen as a neuroprotectant. Trends in Pharmacological Sciences 199920 441-444.

95 Richards CD \& Hesketh TR. Implications for theories of anaesthesia of antagonism between anaesthetic and nonanaesthetic steroids. Nature 1975256 179-182.

96 Bäckström T. Epileptic seizures in women related to plasma estrogen and progesterone during the menstrual cycle. Acta Neurologica Scandinavica $1976 \mathbf{5 4} 321-347$.

97 Bäckström T. Epilepsy in women. Oestrogen and progesterone plasma levels. Experientia 197632 248-249.

98 Kokate TG, Svensson BE \& Rogawski MA. Anticonvulsant activity of neurosteroids: correlation with $\gamma$-aminobutyric acidevoked chloride current potentiation. Journal of Pharmacology and Experimental Therapeutics 1994270 1223-1229.

99 Belelli D, Lan NC \& Gee KW. Anticonvulsant steroids and the GABA/benzodiazepine receptor-chloride ionophore complex. Neuroscience and Biobehavioral Reviews 199014 315-322.

100 Monaghan EP, Navalta LA, Shum L, Ashbrook D \& Lee DA. Initial human experience with ganaxolone, a neuroactive steroid with antiepileptic activity. Epilepsia 199738 1026-1031.

101 Monaghan EP, Harris S, Blum D, Morell M, Beydoun A, AbouKhalil BW et al. Ganaxolone in the treatment of complex partial seizures: a double-blind presurgical design. Epilepsia 38 (Suppl 8) $1997 \mathrm{~S} 179$.

102 Shields WD, Kerrigan JF, Bluestone DL, Nelson TY, Wilner AN, Dodson WE et al. Ganaxolone in the treatment of refractory infantile spasms. Annals of Neurology 199742 503-504.

103 Ströhle A, Romeo E, Hermann B, Pasini A, Spalletta G, di Michele $\mathrm{F}$ et al. Concentrations of 3alpha-reduced neuroactive steroids and their precursors in plasma of patients with major depression and after clinical recovery. Biological Psychiatry $199945274-277$.

104 Ator NA, Grant KA, Purdy RH, Paul SM \& Griffiths RR. Drug discrimination analysis of endogenous neuroactive steroids in rats. European Journal of Pharmacology $1993241237-243$.

105 Biedermann K \& Schoch P. Do neuroactive steroids cause fatigue in pregnancy? European Journal of Obstetrics, Gynecology and Reproductive Biology 199558 15-18.

106 Rupprecht R. The neuropsychopharmacological potential of neuroactive steroids. Journal of Psychiatric Research 199731 297-314.

107 Wang M, Seippel L, Purdy RH \& Bäckström T. Relationship between symptom severity and steroid variation in women with premenstrual syndrome: study on serum pregnenolone, pregnenolone sulfate, 5 alpha-pregnane-3,20-dione and 3 alpha-hydroxy-5 alpha-pregnan-20-one. Journal of Clinical Endocrinology and Metabolism 199681 1076-1082.

108 Concas A, Mostallino MC, Porcu P, Follesa P, Barbaccia ML, Trabucchi $M$ et al. Role of brain allopregnanolone in the plasticity of $\gamma$-aminobutyric acid type A receptor in rat brain during pregnancy and after delivery. PNAS $19989513284-$ 13289.

109 Smith SS, Gong QH, Li X, Moran MH, Bitran D, Frye CA et al. Withdrawal from $3 \alpha-\mathrm{OH}-5 \alpha$-pregnan-20-one using a pseudopregnancy model alters the kinetics of hippocampal $\mathrm{GABA}_{\mathrm{A}}$ gated current and and increases the GABAA receptor $\alpha 4$ subunit in association with increased anxiety. Journal of Neuroscience $1998 \mathbf{1 8} 5275-5284$.

110 Romeo E, Brancati A, De Lorenzo A, Fucci P, Furnari C, Pompili E et al. Marked decrease of plasma neuroactive steroids during alcohol withdrawal. Clinical Neuropharmacology 1996 19 366-369.

111 Orentreich N, Brind JL, Vogelman JH, Andres R \& Baldwin H. Long-term longitudinal measurements of plasma dehydroepiandrosterone sulfate in normal men. Journal of Clinical Endocrinology and Metabolism 199275 1002-1004.
112 Goodyer IM, Herbert J, Altham PM, Pearson J, Secher SM \& Shiers HM. Adrenal secretion during major depression in 8- to 16-year olds. I Altered diurnal rhythms in salivary cortisol and dehydroepiandrosterone (DHEA) at presentation. Psychological Medicine 199626 245-256.

113 Kimonides VG, Khatibi NH, Svendsen CN, Sofroniew MV \& Herbert J. Dehydroepiandrosterone (DHEA) and DHEA-sulfate (DHEAS) protect hippocampal neurons against excitatory amino acid-induced neurotoxicity. PNAS $1998951852-$ 1857.

114 Näsman B, Olsson B, Bäckström T, Eriksson S, Grankvist K, Viitanen $\mathrm{M}$ et al. Serum dehydroepiandrosterone sulfate in Alzheimer's disease and in multiinfarct dementia. Biological Psychiatry $199130684-690$.

115 Magri F, Terenzi F, Ricciardi T, Fioravanti M, Solerte SB, Stabile $\mathrm{M}$ et al. Association between changes in adrenal secretion and cerebral morphometric correlates in normal aging and senile dementia. Dementia and Geriatric Cognitive Disorders 200011 90-99.

116 Hillen T, Lun A, Reischies FM, Borchelt M, SteinhagenThiessen E \& Schaub RT. DHEA-S plasma levels and incidence of Alzheimer's disease. Biological Psychiatry 200047 161-163.

117 Wolf OT, Neumann O, Hellhammer DH, Geiben AC, Strasburger CJ, Dressendörfer RA et al. Effects of a two-week physiological dehydroepiandrosterone substitution on cognitive performance and well-being in healthy elderly women and men. Journal of Clinical Endocrinology and Metabolism $1997 \mathbf{8 2}$ 2363-2367.

118 Wolf OT, Naumann E, Hellhammer DH \& Kirschbaum C. Effects of dehydroepiandrosterone replacement in elderly men on event-related potentials, memory and well-being. Journal of Gerontology Series A, Biological Sciences and Medical Sciences 199853 M385-M390.

119 Huppert FA, Van Niererk JK \& Herbert J. Dehydroepiandrosterone (DHEA) supplementation for cognition and well-being. The Cochrane Database of Systematic Reviews 20002 CD000304.

120 Hampson E. Oestrogen-related variations in human spatial and articulatory motor skills. Psychoneuroendocrinology 199015 97-111.

121 Phillips S \& Sherwin B. Effects of oestrogen on memory function in surgically menopausal women. Psychoneuroendocrinology $199217485-495$.

122 Phillips S \& Sherwin B. Variations in memory function and sex steroid hormones across the menstrual cycle. Psychoneuroendocrinology 199217 497-506.

123 Gibbs RB. Estrogen and nerve growth-factor related systems in the brain. Annals of the New York Academy of Sciences $1994 \mathbf{7 4 3}$ 165-196.

124 McEwen BS. Steroid hormone actions on the brain. When is the genome involved? Annals of the New York Academy of Sciences 1994743 396-405.

125 McEwen BS, Gould E, Orchinik M, Weiland NG \& Wooley CS. Oestrogen and the structural and functional plasticity of neurons: implications for memory, ageing and neurodegenerative processes. Neurology $1995 \mathbf{4 5} 52-73$.

126 McEwen BS, Alves SE, Bulloch K \& Weiland NG. Ovarian steroids and the brain: implications for cognition and aging. Neurology 7 (Suppl 48) 1997 S8-S15.

127 McEwen BS \& Alves SE. Estrogen actions in the central nervous system. Endocrine Reviews 199920 279-307.

128 Henderson VW, Paganini-Hill A, Emanuel CK, Dunn ME \& Buckwalter JG. Oestrogen replacement therapy in older women: comparisons between Alzheimer's disease and nondemented controls. Archives of Neurology 199451 896-900.

Received 13 June 2001

Accepted 21 August 2001 